\title{
Capsule Commentary on Lin et al., "Association of Opioid Overdose Risk Factors and Naloxone Prescribing in US Adults
}

\author{
Michelle S. Keller, PhD, MPH \\ Division of General Internal Medicine, Department of Medicine, Cedars-Sinai Medical Center, Los Angeles, CA, USA.
}

J Gen Intern Med 35(2):620

DOI: $10.1007 / \mathrm{s} 11606-019-05500-\mathrm{x}$

(c) Society of General Internal Medicine 2019

$\mathrm{T}$ his claims-based analysis by Lin et al. matched patients with opioid and naloxone prescription fills with patients receiving only opioids to examine patient-level factors associated with naloxone fills from 2014 to $2017 .^{1}$ The authors analyzed naloxone fills among patients at high risk of opioid overdose, having either high daily doses, concurrent benzodiazepine prescriptions, diagnosis of opioid use disorder, or history of overdose.

The authors' findings are a cause for concern. Lin et al. found that fewer than $2 \%$ of patients at high risk for overdose filled a script for naloxone during the study period. The authors also found no association between having a history of opioid overdose or other substance use disorders, diagnoses which increased significantly during the study period, and a naloxone fill. Lin et al.'s findings echo a recent report from the Centers for Disease Control and Prevention (CDC) which found that despite increases in naloxone dispensing, only one of every 69 high-dose prescriptions was dispensed with a naloxone prescription. ${ }^{2}$ A potential barrier identified in the CDC analysis was cost: two-thirds of naloxone prescriptions required out-of-pocket costs. Other barriers discussed by Lin et al. include lack of clinician training and comfort with discussing the use of naloxone. Policymakers, insurers, and health systems should address these important barriers to reduce potential overdose deaths. From 2013 to 2017, drug overdoses increased in most states, ${ }^{3}$ and of the 70,237 drug overdoses reported in 2017, two out of three overdoses involved opioids. ${ }^{2}$ Although the rise in overdose deaths is largely attributed to illicit synthetic opioids, there remain important opportunities for primary care clinicians to prevent opioidrelated overdoses through naloxone prescriptions.

Strengths of this study include the large dataset $(N=$ $23,778)$, which includes data from commercially insured adults and seniors with Medicare Advantage across 50 states, and the analysis of naloxone fill trends over time. Limitations include the inability to capture naloxone receipt from community distribution programs and the lack of data about naloxone prescriptions versus fills that would enable identification of target populations with barriers to fill prescriptions. In short, Lin and authors highlight critical areas for improvement in preventing opioid overdoses.

Corresponding Author: Michelle S. Keller, PhD, MPH; Division of General Internal Medicine, Department of Medicine, Cedars-Sinai Medical Center, Los Angeles, CA, USA (e-mail: Michelle.keller@cshs. org).

\section{Compliance with Ethical Standards:}

Conflict of Interest: The author declares that she has no conflict of interest.

Publisher's Note: Springer Nature remains neutral with regard to jurisdictional claims in published maps and institutional affiliations.

\section{REFERENCES}

1. Lin L, Brummett CM, Waljee JF, Englesbe MJ, Gunaseelan V, Bohnert AB. Association of opioid overdose risk factors and naloxone prescribing in US adults. J Gen Intern Med. https://doi.org/10.1007/s11606-01905423-7.

2. Guy GP. Vital Signs: Pharmacy-Based Naloxone Dispensing-United States, 2012-2018. MMWR Morb Mortal Wkly Rep. 2019;68.

3. Scholl L, Seth P, Kariisa M, Wilson N, Baldwin G. Drug and opioidinvolved overdose deaths-United States, 2013-2017. MWWR Morb Mortal Wkly Rep. 2019;67(5152):1419.

Publisher's Note Springer Nature remains neutral with regard to jurisdictional claims in published maps and institutional affiliations. 